\title{
R-CURVE EVALUATION OF PIPELINE GIRTH WELDS USING ADVANCED MEASUREMENT TECHNIQUES
}

\author{
N. Geldhof ${ }^{1}$, J. Van Iseghem ${ }^{1}$, M. Verstraete ${ }^{1}$, S. Hertelé ${ }^{1}$, K. Van Minnebruggen ${ }^{1}$ and W. De \\ Waele $^{1}$ \\ ${ }^{1}$ Ghent University, Laboratory Soete, Belgium
}

\begin{abstract}
A strain-based flaw assessment procedure is recommended for girth welded pipelines subjected to large deformations. To evaluate the allowable defect dimensions, the tearing resistance needs to be characterized. This paper investigates the effect of weld metal strength mismatch on the resistance curve using Single Edge Notched Tension (SENT) specimens. Several advanced measurement techniques are applied during the tests in order to obtain a continuous measurement of crack extension and to visualize the deformation fields near the crack. The resistance curves are determined using a single specimen technique. The unloading compliance method and the potential drop method result in similar predictions of ductile crack extension, yielding similar resistance curves. Next to these measurements, the full field deformations are determined using digital image correlation. The experiments indicate that the position of the applied notch in the weld has the potential to influence the strain fields.
\end{abstract}

Keywords: SENT, tearing resistance, unloading compliance, potential drop, weld metal, mismatch

\section{INTRODUCTION}

Some pipelines may become subjected to natural phenomena that cause large deformations, e.g. ground movements due to discontinuous permafrost or seismic activity. In such conditions a strain-based design, which allows for plastic deformation, is preferred over a conventional stress-based design [1, 2]. The pipeline's girth welds unavoidably contain defects that, if not assessed properly, start growing upon loading and potentially cause failure. It is impossible to detect all defects and for economical reasons it is not possible to repair all of them. To assess the severity of girth weld defects, a tearing resistance curve (R-curve) is typically needed as input for analytical flaw assessment procedures (e.g. [3]). This R-curve expresses the amount of ductile crack extension $(\Delta a)$ as a function of the fracture toughness, commonly expressed in terms of $C T O D$ (Crack Tip Opening Displacement). This research is of great relevance, since it covers repair decisions that can save or cost millions of dollars $[4,5]$.

The recommended testing procedure to obtain the resistance curve is the SENT (Single Edge Notched Tension) procedure $[3,4,6-8]$. SENT testing reduces the conservatism compared to SENB (Single Edge Notch Bending) testing, since the crack tip constraint matches closer that of a defect in a pipeline girth weld $[4,7,9,10]$. On the other hand, the SENB testing procedure is fully described in the ASTM E1820 [11], whereas, no standardized procedure is available for SENT single-specimen testing. This paper presents the approach towards and results of R-curve testing on welded SENT specimens. The presented procedure is the result of years of experience at Laboratory Soete of Ghent University. Up to date the influence of the loading and clamping conditions, the side groove design and the initial depth have been examined for base metal specimens [12]. The main goal of this paper is to evaluate the unloading compliance (UC) and potential drop (PD) measurement methods for clamped SENT tests on welded specimens. Weld metal centre line defects are investigated by means of two example cases: an even-matched SAW weld and an overmatched GMAW weld.

\section{EXPERIMENTAL SETUP}

\subsection{SENT testing}

The SENT specimens are taken along the pipe's axis, symmetrically to the girth weld (Figure 1). A notch with initial depth $a_{0}$ is applied from the inner diameter by a two-step milling process over the entire width $B$. This results in a final notch radius of $75 \mu \mathrm{m}$. The specimen has a square cross section with a width $B$ equal to $W$. At the cracked ligament a local thickness reduction of the specimen (15\% width reduction) is created by means of side grooves. In the absence of side grooves the crack tip would be subjected to a bi-axial stress state near the free surface, in contrast to the tri-axial stress inside the specimen. This is known to cause crack tunnelling, i.e. the crack grows less at the free surface [13-15]. A width reduction of $15 \%$ leads 
to a more uniform crack front which eases the final crack extension measurement and facilitates the interpretation of the UC and PD measurements $[9,16]$.

The tests are carried out under displacement control, with a loading rate of $0.01 \mathrm{~mm} / \mathrm{sec}$ aiming to represent quasi-static loading conditions. The specimen is clamped using hydraulic grips that prevent rotation of the specimen's end, indicated by the marked area in Figure 1. The daylight grip length $(H)$ between the two clamps equals ten times the specimen width. An overview of the geometrical properties is provided in Table 1.

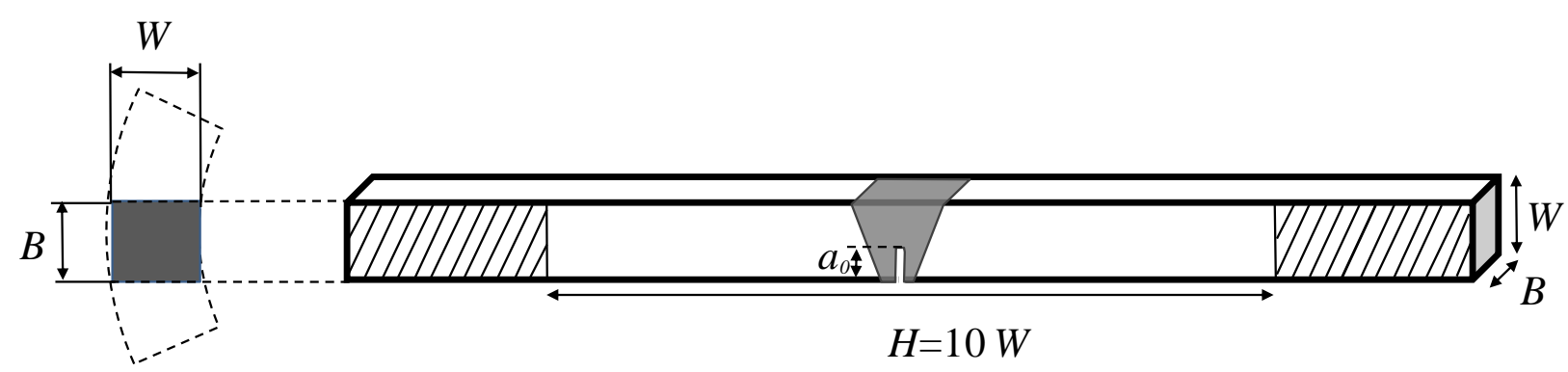

Figure 1: SENT specimen

Table 1: Geometrical parameters of the SENT specimens

\begin{tabular}{|c|c|c|c|}
\hline$a_{0}[\mathrm{~mm}]$ & $B[\mathrm{~mm}]$ & $W[\mathrm{~mm}]$ & $H[\mathrm{~mm}]$ \\
\hline 6.25 & 12.5 & 12.5 & 125 \\
\hline
\end{tabular}

\subsection{Material}

This paper discusses the results of two different welds made in a similar linepipe steel. Three SENT tests are carried out per weld. Base metal properties were determined using full thickness rectangular specimens taken in the longitudinal (pipe axis) direction. Round bar specimens taken along the circumferential direction were used for the weld metal characterization. The specimens 3B1, 3B2 and 3B3 contain a Submerged Arc Weld (SAW). The strength properties are approximately matching those of the base metal (Table 2). The specimens B1, B2 and B3 contain a Gas Metal Arc Weld (GMAW) and are strongly overmatched with respect to the base metal (Table 2).

Table 2: Strength properties of linepipe steel and welds

\begin{tabular}{|c|c|c|c|c|}
\hline \multicolumn{2}{|c|}{} & Yield Strength [MPa] & Flow Strength [MPa] & Tensile Strength [MPa] \\
\hline \multicolumn{2}{|c|}{ Base material } & 560 & 588 & 615 \\
\hline \multirow{3}{*}{ 3B1, 3B2, 2B3 } & SAW weld & 536 & 590 & 645 \\
\cline { 2 - 5 } & Mismatch [\%] & -4.3 & -0.1 & 3.8 \\
\hline \multirow{3}{*}{ B1, B2, B3 } & GMAW weld & 751 & 781 & 811 \\
\cline { 2 - 5 } & Mismatch [\%] & 34.4 & 33.7 & 33.1 \\
\hline
\end{tabular}

\subsection{Measurement techniques}

\subsubsection{CTOD}

When a tensile load is applied, the initial notch with depth $a_{0}$ (grey dotted line in Figure 2) blunts and its flanks open [8, 17]. Associated with this blunting, is a small crack extension $\Delta a_{B}$. Following this blunting phase, a sharp crack initiates. To evaluate the applied load to the crack, the crack mouth opening displacement $(C M O D)$ and crack tip opening displacement $(C T O D)$ are monitored. The $C M O D$ is the displacement between the two notch faces at the specimen surface. The CTOD is defined based on the $90^{\circ}$ 
intercept method, following the original definition by Rice [18]. To measure the $C M O D$ and the $C T O D$, two clip gauges are attached to knives, connected to the surface of the SENT specimen. A first clip gauge is mounted at a height $h_{1}=2.0 \mathrm{~mm}$ and measures the displacement $V 1$. The second is mounted at a height $h_{2}=8.0 \mathrm{~mm}$ and measures the displacement V2. CMOD and CTOD are obtained through trigonometry, using equation (1) and (2) respectively.

$$
\begin{gathered}
C M O D=\frac{V 1 h_{2}-V 2 h_{1}}{h_{2}-h_{1}} \\
C T O D=\left(V 1-\frac{a_{0}+h_{1}}{h_{2}-h_{1}}(V 2-V 1)\right)\left(1+\frac{\frac{V 2-V 1}{2}}{h_{2}-h_{1}}\right)
\end{gathered}
$$

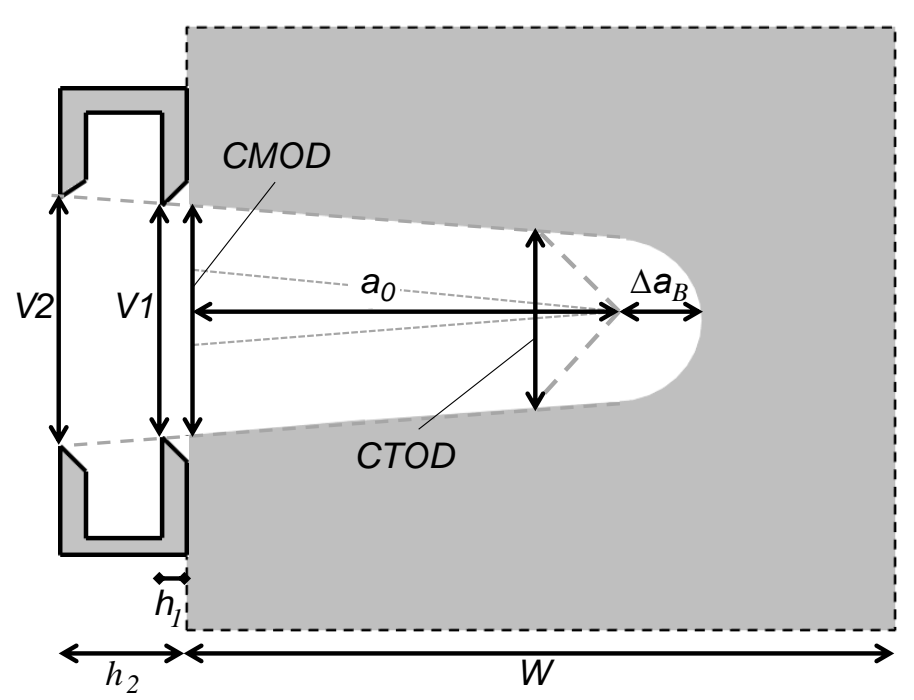

Figure 2: CMOD and CTOD measurement with double clip gage setup

\subsubsection{Unloading compliance (UC)}

During the test, the specimen is partially unloaded and reloaded at fixed predefined $C M O D$ intervals, as illustrated in Figure 3a. From these unloading cycles the compliance $\left(C=\frac{\triangle C M O D}{\Delta F}\right)$ is evaluated [19] and subsequently the crack depth is calculated using an analytical procedure derived by Fonzo et al. [20]. These equations are summarized below (equations (3) and (4)). The coefficients $c_{i}$ are listed in Table 3.

$$
\begin{gathered}
u=\frac{1}{1+\sqrt{B E C_{i}}} \\
a_{i}=\left(c_{0}+c_{1} u+c_{2} u^{2}+c_{3} u^{3}+c_{4} u^{4}+c_{5} u^{5}\right) W
\end{gathered}
$$

Table 3: Coefficients of equation (4)

\begin{tabular}{|c|c|}
\hline Term & Value \\
\hline$c_{0}$ & 1.64461 \\
\hline$c_{1}$ & -8.70840 \\
\hline$c_{2}$ & 30.31342 \\
\hline$c_{3}$ & -69.60922 \\
\hline$c_{4}$ & 83.52325 \\
\hline$c_{5}$ & -39.11201 \\
\hline
\end{tabular}


When the measured compliances are plotted as function of $C M O D$ (e.g. Figure $3 \mathrm{~b}$ ), two distinct regions are identified. In the first region the compliance decreases, which according to equation 4 would imply crack closure. This "apparent negative crack extension" is unrealistic and attributed to (both elastic and plastic) rotation of the specimen. In the second region the compliance increases drastically as a consequence of crack extension. Crack initiation is assumed at the deepest point, as advised in [21]. Accordingly, only the compliances from this initiation point onwards are considered for the evaluation of ductile crack extension $\Delta a$.

(a)

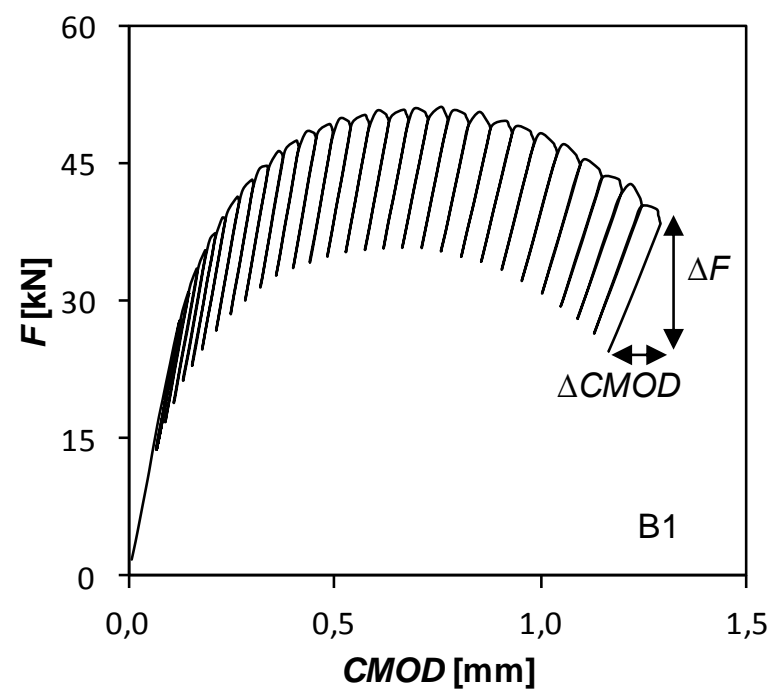

(b)

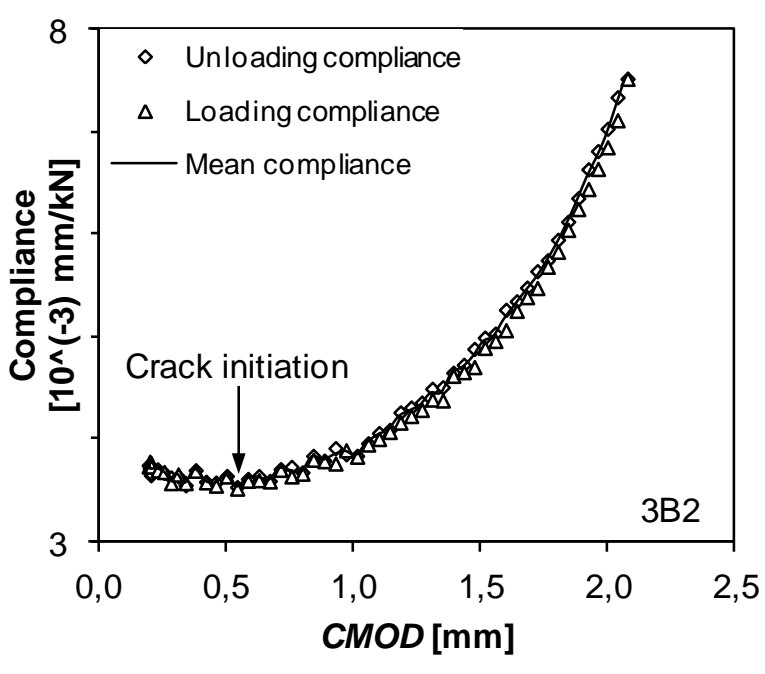

Figure 3: Force vs CMOD of test B1 (a) and compliance vs CMOD of test 3B2 (b)

\subsubsection{Potential drop (PD)}

A second method to measure ductile crack extension is the potential drop technique. A constant DC current $\left(I_{\text {in }}=-I_{\text {out }}=25 \mathrm{~A}\right)$ is forced through the specimen (Figure 4). The voltage difference ('potential drop') over the crack is measured (crack PD). As the crack grows, the electric resistance increases and the voltage also increases according to Ohm's law. To eliminate the detrimental influence of e.g. temperature changes or electric leakage paths, a voltage difference is also measured remote from the crack (reference PD). This zone should be shielded from plastic deformation, since this plastic deformation has the potential to increase the measured voltage.

To determine the crack depth, the crack PD is divided by the reference PD; a dimensionless normalized PD is found (triangular dots in Figure 5). At this point the potential drop has been filtered from the negative effects (e.g. temperature changes). The first measurements proceed linear as function of the $C M O D$, which is expected during the blunting phase and attributed to an increase of the plasticity near the crack tip [22, 23]. After crack initiation, the potential drop increases more than linear. To compensate for the linear increase attributed to the plasticity, this linear trend is subtracted from the normalized PD (solid line in Figure 5). This signal is subsequently shifted to start at unity; the adapted PD is found. The adapted PD is also dimensionless and represents the potential drop which is solely attributed by the crack extension $\Delta a$.

The adapted PD is finally used in the Johnson equation (5) to determine the crack depth, where $y$ is the distance between the crack and the position of one voltage cable for measurement of the crack PD [24].

$$
\frac{\text { adapted } P D(a)}{\text { adapted } P D\left(a_{0}\right)}=\frac{\cosh ^{-1}\left(\frac{\cosh (\pi y / W)}{\cosh (\pi a / W)}\right)}{\cosh ^{-1}\left(\frac{\cosh (\pi y / W)}{\cosh \left(\pi a_{0} / W\right)}\right)}
$$




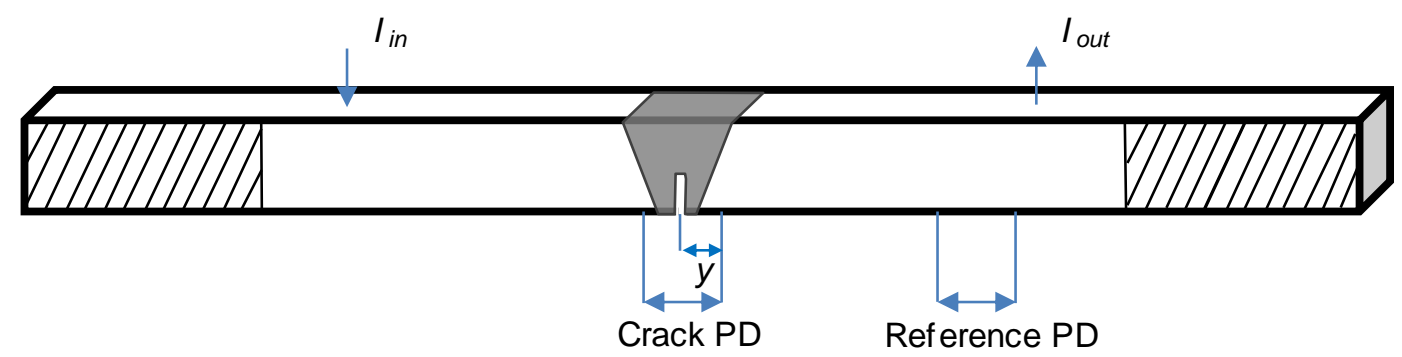

Figure 4: Outline of PD measurement

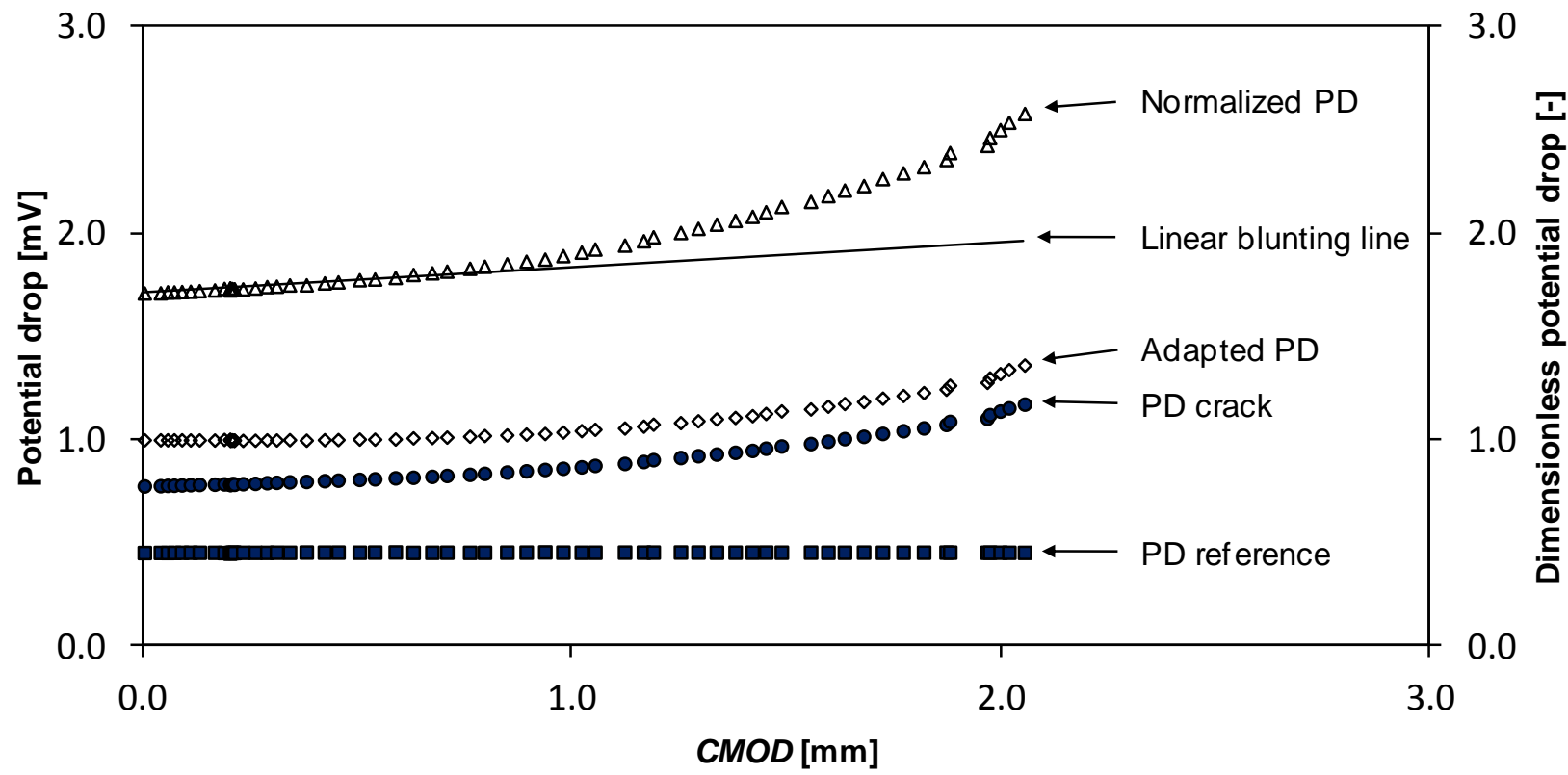

Figure 5: Potential drop in function of $C M O D$ for test 3B2

\subsubsection{Crack growth evaluation}

After completion of each test, the amount of ductile crack extension was evaluated. Therefore, the specimens were first heat-tinted by placing them in an oven on $200^{\circ} \mathrm{C}$ for 3 hours. Two specimens (3B1 and B1) were subsequently broken up in a brittle way after cooling them down in liquid nitrogen. For these specimens the amount of ductile crack extension is evaluated using the nine-points average method described by ASTM E1820 [11]. For the other specimens the amount of ductile crack extension and the crack path was evaluated at mid-thickness on the basis of a cross-sectional macrograph.

\section{RESULTS}

\subsection{Unloading Compliance (UC)}

According to Landes [25], the crack growth during the blunting phase $\triangle a_{B}$ equals half of the CTOD up to the point of ductile crack initiation. This results in a linear initial phase, plotted in Figure 6 ('blunting line'). After initiation, $\Delta a_{B}$ remains constant (see equation (6)) and is added to the ductile crack extension.

$$
\Delta a_{B}=\frac{C T O D_{\text {initiation }}}{2}
$$

The total crack growth is denoted as $\Delta a$. A standardized curve (see equation (7)) is least squares curve fitted through these data [11].

$$
C T O D=\alpha \Delta a^{\beta}
$$


The data considered are contained between two offset lines, parallel to the blunting line. A first offset line crosses the $\Delta a$-abscissa at $0.15 \mathrm{~mm}$ crack extension and the second offset line crosses the $\Delta a$-abscissa at $1.5 \mathrm{~mm}$ crack extension. An overview of the individual regression constants are given in Table 4 .

Table 4: Regression constants of R-curves based on UC data

\begin{tabular}{|l|c|c|}
\hline & $\alpha$ & $\beta$ \\
\hline 3B1 & 1.1337 & 0.5163 \\
\hline 3B2 & 1.1740 & 0.5493 \\
\hline 3B3 & 1.1790 & 0.5244 \\
\hline 3B (fit) & $\mathbf{1 . 1 6 2 3}$ & $\mathbf{0 . 5 2 9 9}$ \\
\hline B1 & 0.5885 & 0.4790 \\
\hline B2 & 0.6558 & 0.5191 \\
\hline B3 & 0.6900 & 0.4906 \\
\hline B (fit) & $\mathbf{0 . 6 4 4 8}$ & $\mathbf{0 . 4 9 6 5}$ \\
\hline
\end{tabular}

The fitted R-curves (i.e. the mean of the three fitting curves of the same material) are plotted in Figure 6 . The R-curves of the specimens taken from the same weld are comparable, indicating that the material heterogeneity is limited in terms of tearing resistance and also shows that the measurement methods are robust. In this study, the R-curve of the even-matched specimens, i.e. the 3B series, are higher than the Rcurves of the overmatched specimens. This is in agreement with experimental results reported in literature $[26,27]$.

(a)

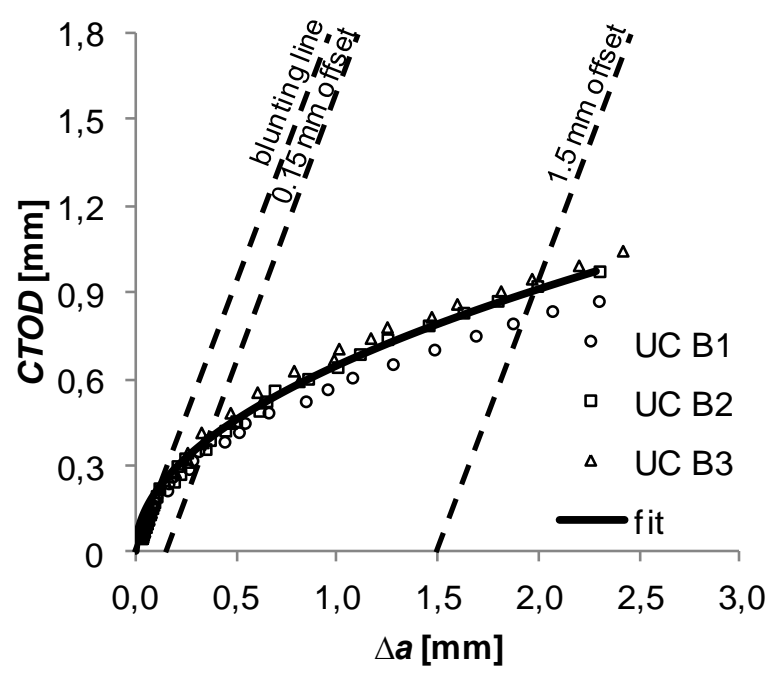

(b)

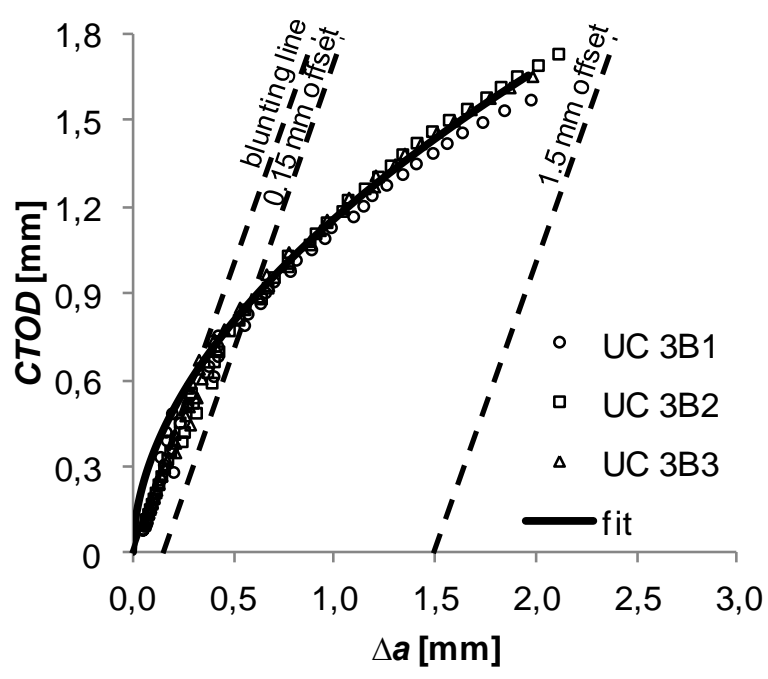

Figure 6: R-curves obtained using the UC method

\subsection{Potential drop (PD)}

The R-curves obtained with the PD method are given in Figure 7. Individual regression constants are given in Table 5. The same observations can be made as for the unloading compliance method.

Table 5: Regression constants of R-curves based on PD

\begin{tabular}{|l|c|c|}
\hline & $\alpha$ & $\beta$ \\
\hline 3B1 & 1.2209 & 0.4397 \\
\hline 3B2 & 1.2003 & 0.5116 \\
\hline 3B3 & 1.0511 & 0.6162 \\
\hline 3B (fit) & $\mathbf{1 . 1 5 8 3}$ & $\mathbf{0 . 5 1 2 5}$ \\
\hline B1 & 0.6324 & 0.4508 \\
\hline B2 & 0.6379 & 0.5611 \\
\hline B3 & 0.7029 & 0.5006 \\
\hline B (fit) & $\mathbf{0 . 6 5 8 1}$ & $\mathbf{0 . 5 0 2 3}$ \\
\hline
\end{tabular}


(a)

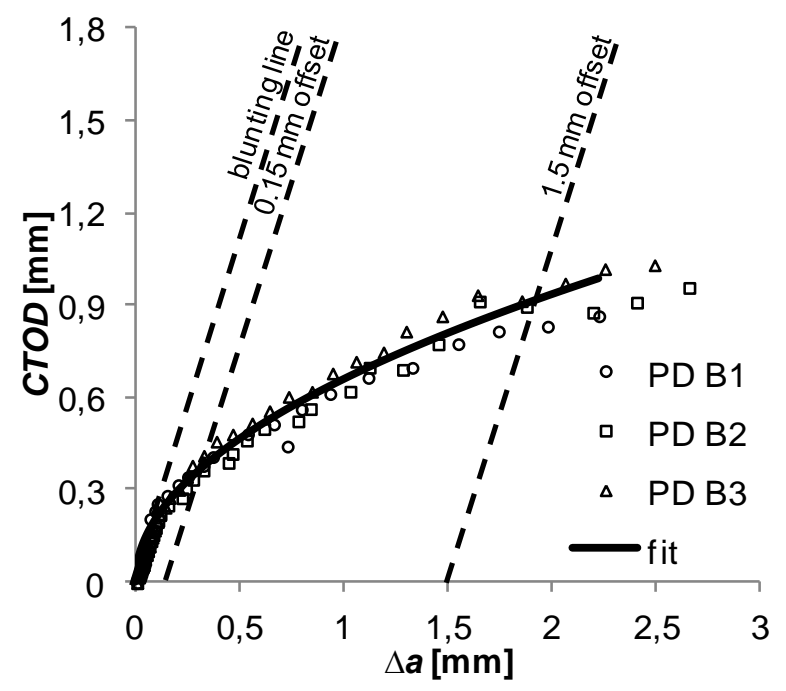

(b)

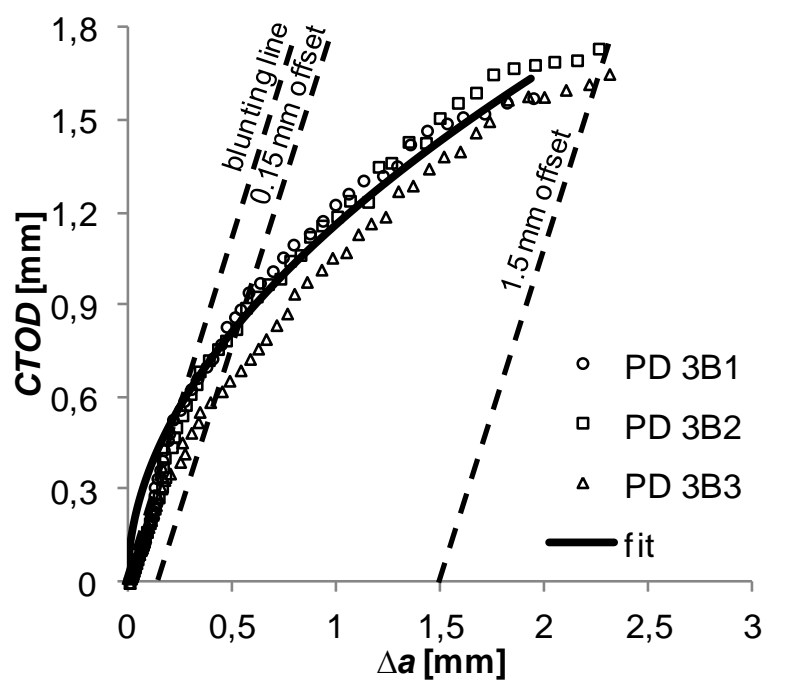

Figure 7: R-curves obtained using the PD method

\section{DISCUSSION}

\subsection{UC versus PD}

The fitted R-curves found with the two methods are compared for all specimens (see Figure 8a). It is concluded that both methods closely correspond. There is a small difference between the calculated final crack depths for both methods. These differences are shown in Figure 8b. However the predicted values differ merely $6 \%$ on average and maximum $14 \%$ which is acceptable with respect to the unavoidable natural scatter of toughness properties.

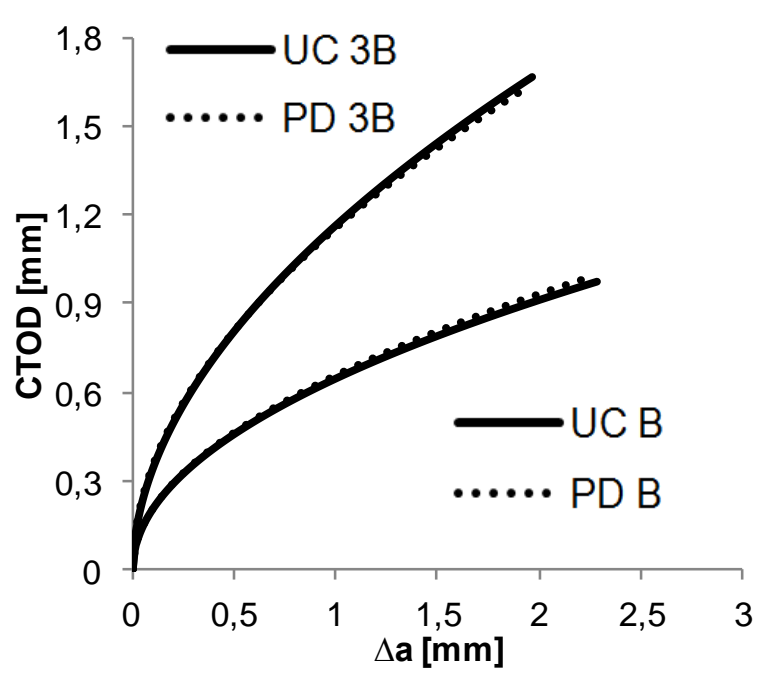

(a)

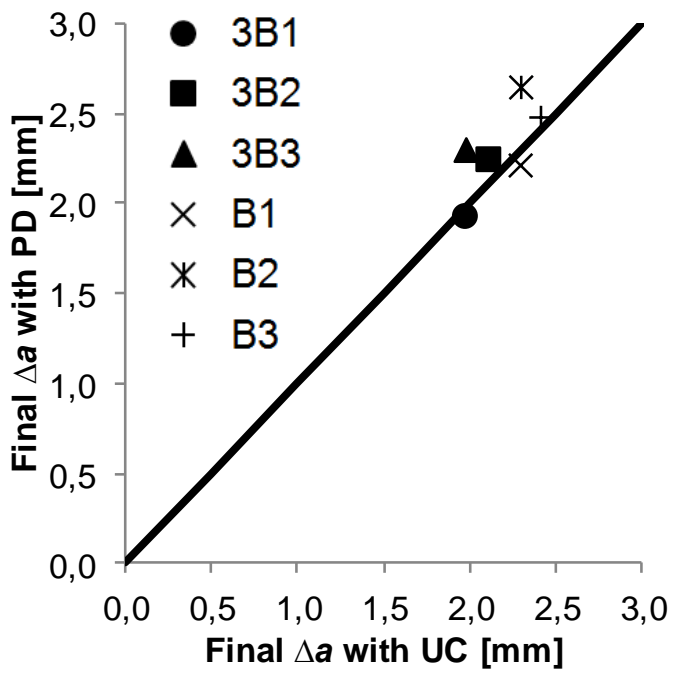

(b)

Figure 8: Comparison of the R-curves obtained using UC and PD for specimens 3B1 and B1 (a) and 3B2 and B2 (b)

\subsection{Accuracy in predicting final ductile crack extension}

For each series of overmatched and even-matched test specimens, one specimen (3B1 and B1 (Figure 9a)) is used to evaluate the final crack extension using the nine-point average method described by ASTM E1820 [11]. The so obtained values for the final crack extension correspond well (maximum $8 \%$ difference) with the predicted final crack extension for both the UC and PD method (solid markers in Figure 10). For the other specimens (3B2, 3B3, B2 and B3) the amount of ductile crack extension and the crack path was evaluated at approximately mid-thickness by making a cross-sectional macrograph (for example test B2 on Figure 9b). The measured crack extension of these macrographs cannot be calculated with the nine-point method because they are cut through in the longitudinal direction. It is furthermore not correct due to the 
crack tunnelling effect. On the crack front of B1 (Figure 9a) for instance, it is clear that the smallest crack extension occurs at the middle. Nevertheless, the macrographs give an indication of the amount of crack extension (open markers in Figure 10).

(a)

B1

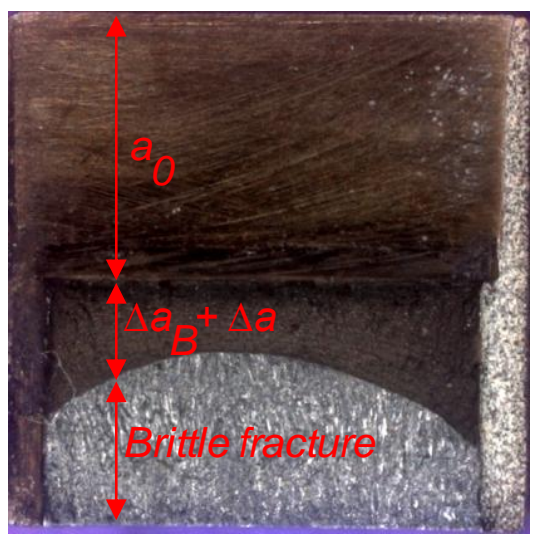

Figure 9: Crack front of B1 (a) and macrograph of B2 (b) (b) (a)

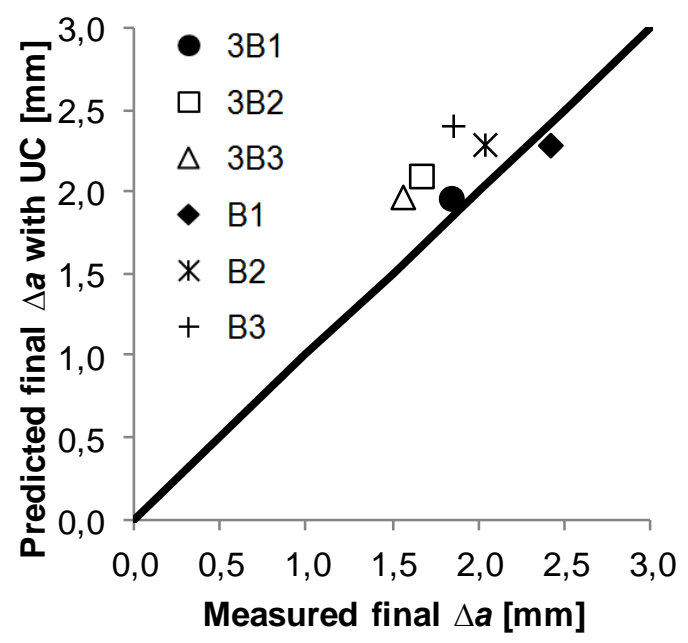

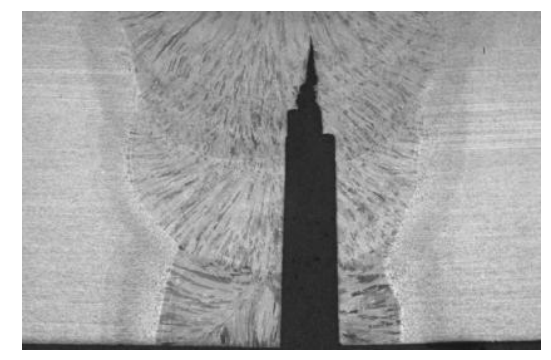

(b)

Figure 10: Comparison between measured and predicted final crack extension

\section{CONCLUSION}

The unloading compliance method and the potential drop method were applied during SENT testing of welded specimens. Their results were evaluated in terms of R-curves and final crack extension. The obtained R-curves for both methods correspond very well. There is a small but acceptable difference between the final crack depths predicted by both techniques. Determination of the final crack depth after test completion with the ASTM nine-point average method proves the accuracy of the predicted final crack depth with both methods.

The difference in tearing resistance between an even-matched and overmatched weld were examined. In this study, the R-curves of overmatched SENT test specimens are lower than those of even-matched SENT test specimens. 


\begin{tabular}{|c|c|c|}
\hline$A$ & Crack depth & $\mathrm{mm}$ \\
\hline$a_{0}$ & Initial notch depth & $\mathrm{mm}$ \\
\hline$\Delta a_{B}$ & Crack extension due to blunting & $\mathrm{mm}$ \\
\hline$\Delta a$ & Total crack extension & $\mathrm{mm}$ \\
\hline$B$ & Width of the specimen & $\mathrm{mm}$ \\
\hline W & Height of the specimen, wall thickness & $\mathrm{mm}$ \\
\hline$h_{1}$ & Height of clip gauge 1 & $\mathrm{~mm}$ \\
\hline$h_{2}$ & Height of clip gauge 2 & $\mathrm{~mm}$ \\
\hline V1 & Displacement measured with clip gauge 1 & $\mathrm{~mm}$ \\
\hline V2 & Displacement measured with clip gauge 2 & $\mathrm{~mm}$ \\
\hline$C M O D$ & Crack mouth opening displacement & $\mathrm{mm}$ \\
\hline CTOD & Crack tip opening displacement & $\mathrm{mm}$ \\
\hline$E$ & Young's elastic modulus & $\mathrm{GPa}$ \\
\hline SMYS & Specified minimum yield strength & $\triangle \mathrm{Pa}$ \\
\hline Y & $\begin{array}{l}\text { Distance between the crack and the position of one } \\
\text { voltage cable from the crack PD }\end{array}$ & $\mathrm{mm}$ \\
\hline$I_{\text {in }}=-I_{\text {out }}$ & Constant DC current & $A$ \\
\hline SENT & Single Edge Notched Tension & \\
\hline SENB & Single Edge Notched Bending & \\
\hline$U C$ & Unloading compliance & \\
\hline$P D$ & Potential drop & \\
\hline$D I C$ & Digital image correlation & \\
\hline SAW & Submerged Arc Weld & \\
\hline GMAW & Gas Metal Arc Weld & \\
\hline
\end{tabular}

\section{ACKNOWLEDGEMENTS}

The authors would like to acknowledge the support of all the technicians who helped succeeding the experiments in the laboratory.

\section{REFERENCES}

[1] D. B. Lillig. (2008) The first ISOPE strain-based design symposium - a review. International Offshore and Polar Engineering conference.

[2] W. C. Kan, M. Weir, M. M. Zhang, D. B. Lillig, S. T. Barbas, M. L. Macia, et al., "Strain-Based Pipelines: Design Consideration Overview," in Proceedings of the Eighteenth (2008) International Offshore and Polar Engineering Conference (ISOPE), Vancouver, BC, Canada, 2008.

[3] P. Fairchild, A. Kibey , H. Tang , R. Krishnam , X. Wang , M. Macia , et al., "Continued advancements regarding capacity prediction of strain-based pipelines," in Proceeding of the 2012 9th International Pipeline Conference, Alberta, Canada, 2012.

[4] W. R. Tyson, G. Shen, J. A. Gianetto, and D.-Y. Park, "Development of a low-constraint SE(T) toughness test," CANMET Material Technology Laboratory Ontario, Canada, 2009.

[5] R. Denys, "Girth weld defect acceptance: workmanship, repair or ECA?," ed. Gent: Laboratory Soete, Ghent University, 2010, pp. 1-21. 
[6] DNV, "Submarine Pipeline Systems," in Offshore Standards DNV-OS-F101, ed: Det Norske Veritas, 2008.

[7] DNV, "Fracture Control for Pipeline Methods Introducing Cyclic Plastic Strain," ed: Recommended Practice DNV-RP-F108.

[8] Y.-Y. Wang, M. Liu, F. Zhang, D. Horsley, and S. Nanney, "Multi-tier tensile strain models for strainbased design PART 1 - fundamental basis," in Proceedings of the 2012 9th International Pipeline Conference IPC2012, Calgary, Alberta, Canada, 2012.

[9] D.-Y. Park, W. R. Tyson, J. A. Gianetto, G.Shen, and R. S. Eagleson, "Evaluation of fracture toughness of $\mathrm{X} 100$ pipe steel using SE(B) and clamped SE(T) single specimens," in Proceedings of the 8th International Pipeline Conference, Alberta, Canada 2010.

[10] M. Chiesa, B. Nyhus, B. Skallerud, and C. Thaulow, "Efficient fracture assessment of pipelines. A constraint-corrected SENT specimen approach," Engineering Fracture Mechanics, vol. 68, pp. 527547, 2001.

[11] ASTM, "E1820-08a," in Standard test method for measurement of fracture toughness, ed: American Society for Testing and Materials, 2008.

[12] M. Verstraete, S. Hertelé, W. De Waele, R. Denys, and K. Van Minnebruggen, "Measurement of ductile crack extension in Single Edge Notch Tensile specimens," presented at the International Conference on Experimental Mechanics, Porto, Portugal, 2012.

[13] H. Tang, M. Macia, K. Minnaar, P. Gioielli, S. Kibey, and D. Fairchild, "Development of the sent test for strain-based design of welded pipelines," 2010.

[14] M. James and J. Newman, "The effect of crack tunneling on crack growth: experiments and ctoa analyses," Engineering Fracture Mechanics, vol. 70, pp. 457-468, 2003.

[15] J. Zuo, X. Deng, M. A. Sutton, and C.-S. Cheng, "Three-dimensional crack growth in ductile materials: Effect of stress constraint on crack tunneling," Journal of Pressure Vessel Technology, vol. 130, 2008.

[16] X.-K. Zhu and J. A. Joyce, "Review of fracture toughness (G, K, J, CTOD, CTOA) testing and standardization," Engineering Fracture Mechanics, vol. 85, pp. 1-46, 1 february 2012.

[17] M. Cauwelier and J. Maelfait, "Evaluatie van ductiele scheuruitbreiding in pijpleidingstaal," afstudeerwerk, Laboratorium Soete, Universiteit Gent, Gent, 2012.

[18] J. R. Rice, "A Path Independent Integral and the Approximate Analysis of Strain Concentration by Notches and Cracks," Journal of Applied Mechanics, vol. 35, pp. 379-386, 1968.

[19] K. Van Minnebruggen and D. Van Puyvelde, "Experimentele evaluatie van plastische vervormingen en scheurgroei in gelaste constructies," afstudeerwerk, Laboratorium Soete, Universiteit Gent, Gent, 2011.

[20] A. Fonzo, G. Melis, L. D. Vito, G. Mannucci, P. Darcis, G. Richard, et al., "Techniques for fracture toughness testing of offshore pipelines," in ASME Conference Proceedings, Honolulu, Hawai, 2009, pp. 249-257.

[21] ExxonMobil, "Measurement of Crack-Tip Opening Displacement (CTOD), Fracture Resistance Curves Using Single-Edge Notched Tension (SENT) Specimens," September 20, 20102010.

[22] G. Wilkowski, D. J. Shim, S. Kalyanam, G. Wall, P. Mincer, D. Rider, et al., "Using D-C electric potential for crack initiation/growth monitoring during testing of weld metal fracture specimens," presented at the Pipeline Technology Conference, Ostend, Belgium, 2009.

[23] C. G. Chipperfield, "Detection and toughness characterisation of ductile crack initiation in 316 stainless steel," International Journal of Fracture, vol. 12, pp. 873-886, 1976.

[24] H. H. Johnson, "Calibrating the electric potential method for studying slow crack growth," Materials Research \& standards, September 19651965.

[25] J. D. Landes, "The blunting line in elastic-plastic fracture," Fatigue Fract. Engng Mater. Struct., vol. 18, pp. 1289-1297, 21 July 1995.

[26] J. R. Gordon, N. Zettlemoyer, and W. C. Mohr, "Crack Driving Force in Pipelines Subjected to Large Strain and Biaxial Stress Conditions," in Proceedings of the Sixteenth (2007) International Offshore and Polar Engineering Conference (ISOPE), Lisbon Portugal, 2007.

[27] M. Liu and Y.-Y. Wang, "Significance of Biaxial Stress on the Strain Concentration and Crack Driving Force in Pipeline Girth Welds with Softened HAZ," in Proceedings of the 26th International Conference on Offshore Mechanics and Arctic Engineering, San Diego, 2007. 